\title{
Effect of feeding high-oleic sunflower oil to dairy cows on the milk fatty acid profile - RESET study
}

\author{
O. Markey ${ }^{1}$, K. E. Kliem ${ }^{2}$, D. J. Humphries ${ }^{2}$, R. Morgan ${ }^{2}$, D. Vasilopoulou ${ }^{1,2}$, A. Grandison ${ }^{1}$, \\ C. Fagan ${ }^{1}$, S. Todd ${ }^{3}$, K. G. Jackson ${ }^{1}$, J. A. Lovegrove ${ }^{1}$ and D. I. Givens ${ }^{2}$ \\ ${ }^{1}$ Hugh Sinclair Unit of Human Nutrition and Institute for Cardiovascular and Metabolic Research, Department of \\ Food and Nutritional Sciences, ${ }^{2}$ Food Production and Quality Division and ${ }^{3}$ Department of Mathematics and Statistics, \\ University of Reading, Reading, RG6 6 AP
}

There is an urgent need to focus on modifiable risk factors for CVD, including a high intake of saturated fatty acids (SFA). Milk and dairy products (excluding butter) contribute $22-25 \%$ of mean daily intake of SFA in UK adults ${ }^{(1)}$. One strategy for reducing SFA intake is removal or reduction of dairy intake. However, manipulation of the fatty acid (FA) profile of milk offers a sustainable means of reducing SFA intake at a population level, whilst still retaining the beneficial aspects of dairy foods ${ }^{(2,3)}$ and preventing SFA re-entering the food chain. As part of the RESET (REplacement of SaturatEd fat in dairy on Total cholesterol) study, the effect of feeding high-oleic sunflower oil (HOS; $\sim 85 \%$ monounsaturated fatty acids (MUFA)) on the FA composition of ruminant winter milk was determined.

The habitual total mixed ration diet of 30 multiparous Holstein-Friesian cows in mid-lactation was supplemented with $1 \mathrm{~kg} / \mathrm{cow} / \mathrm{d}$ HOS (AAK, UK), for a $21 \mathrm{~d}$ period, with the aim of producing milk fat containing a lower proportion of SFA and a higher cis-MUFA content. Pooled milk from these cows was analysed in triplicate for FA composition by gas chromatography, and the results compared with commercially available control milk.

\begin{tabular}{lll}
\hline & \multicolumn{2}{l}{ Fatty acid profile of milk fat $(\mathrm{g} / 100 \mathrm{~g}$ total FA) } \\
\cline { 2 - 3 } & Modified milk & Control milk \\
\hline$\sum$ SFA & $54 \cdot 0$ & $71 \cdot 8$ \\
$\sum$ cis-MUFA & $32 \cdot 3$ & $21 \cdot 5$ \\
$\sum$ trans-MUFA & $10 \cdot 2$ & $3 \cdot 4$ \\
$\sum$ MUFA & $42 \cdot 4$ & 24.9 \\
$\sum 18: 1$ cis total & $29 \cdot 9$ & $19 \cdot 0$ \\
$\sum 18: 1$ trans total & $9 \cdot 6$ & $3 \cdot 0$ \\
\hline
\end{tabular}

HOS supplementation of the cows' diets for $21 \mathrm{~d}$ resulted in lower SFA and higher cis-MUFA and trans-FA concentrations than control milk. HOS supplementation was also associated with a lower total fat content $(2 \cdot 8 \mathrm{~g} / 100 \mathrm{~g})$ than that typically observed in commercially available whole milk. These data illustrate that supplementation of the dairy cow diet with $1 \mathrm{~kg} / \mathrm{cow} / \mathrm{d}$ HOS is an effective strategy for lowering the SFA content of milk and successfully reducing saturated fat in the food chain. Increases in trans-FA concentrations, were also observed, yet it is unclear whether there are effects of ruminant $\operatorname{trans}^{-F A}$ on CVD risk ${ }^{(3)}$. In a randomised, crossover, double blind, controlled study (ClinicalTrials.gov NCT02089035), future work will determine whether modified, SFA-reduced dairy product consumption improves vascular function and other CVD risk markers.

This research was supported by the Medical Research Council (MR/K020218/1). Control cows' milk was supplied in kind by Arla Foods and HOS was supplied in kind by AarhusKarlshamn (AAK) UK.

1. Department of Health (2011) National Diet and Nutrition Survey: Headline results from Years 1 and 2 (combined) of the rolling programme 2008/ 9-2009/10

2. Givens et al. (2009) Animal 3: 1067-74.

3. Markey et al. (2014) Nutr Bull (In press). 